\title{
Original Manuscript \\ Bilateral Branch Pulmonary Artery Valve Implantation in Repaired Tetralogy of
}

\section{Fallot}

Neha Bansal ${ }^{1}$, M.D., Daisuke Kobayashi ${ }^{1}$, M.D., Thomas J. Forbes ${ }^{1}$, M.D., Wei Du,

Ph.D., ${ }^{2}$ Jeffrey M Zerin, M.D. ${ }^{3}$, Aparna Joshi, M.D. ${ }^{3}$ Daniel R. Turner ${ }^{1}$, M.D.

\section{${ }^{1}$ Division of Cardiology, Children's Hospital of Michigan, Carmen and Ann Adams}

Department of Pediatrics, Wayne State University School of Medicine, Detroit, MI, USA

${ }^{2}$ Wayne State University, Department of Pediatrics, Detroit, Michigan.

${ }^{3}$ Department of Radiology, Children's Hospital of Michigan, Detroit, MI, USA.

\section{Corresponding author:}

Neha Bansal, MD

Division of Cardiology, Children's Hospital of Michigan, Carman and Ann Adams

Department of Pediatrics, Wayne State University School of Medicine

3901 Beaubien Boulevard, Detroit, MI 48201, USA

Telephone: 313-745-5835

Fax: 313-993-0894

E-mail:nbansal@dmc.org

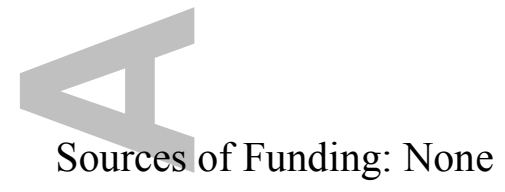

This is the author manuscript accepted for publication and has undergone full peer review but has not been through the copyediting, typesetting, pagination and proofreading process, which may lead to differences between this version and the Version of record. Please cite this article as doi:10.1002/ ccd.27489. 


\section{Conflicts of Interest/ Disclosures: None}
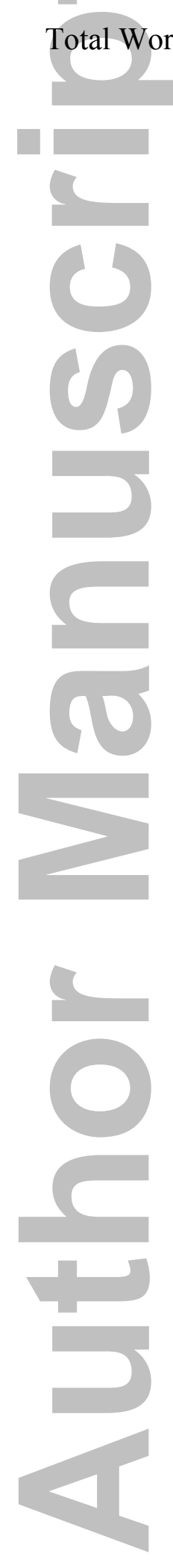

Catheterization and Cardiovascular Interventions

This article is protected by copyright. All rights reserved. 


\section{ABSTRACT (Total 294 words)}

Background: Transcatheter, bilateral branch pulmonary artery (PA) valve implantation is a novel treatment for patients with severe pulmonary insufficiency and oversized right ventricle (RV) outflow tract. There is scarce data on efficacy and safety of this approach. Methods: This was a retrospective study of 8 patients with repaired Tetralogy of Fallot who underwent bilateral branch PA valve implantation. Demographics, echocardiography, cardiac catheterization, and axial imaging data were reviewed. Variables were compared by a paired sample t-test.

Results: All patients were adult sized (weight $43-99 \mathrm{~kg}$ ) with oversized RV outflow tract not suitable for conventional transcatheter pulmonary valve implantation. Staged bare metal PA stenting followed by valve implantation (interval 3-5 months) was technically successful in 7 patients with one stent embolization. In another patient proximal stent migration prevented placement of bilateral pulmonary valve stents. There were a total of 14 valved branch PA stents placed (Melody valve $n=9$, Sapien XT $n=2$, Sapien $3 n=3$ ). In the 7 patients undergoing successful branch pulmonary valve placement, at median follow up of 10 months (range 3 months to 6 years), 13 (93\%) valves had none/trivial insufficiency on echocardiography. Pre- and post-valve implantation cardiac magnetic resonance imaging in five patients showed significant reduction of indexed RV end-diastolic volume $\left(152 \pm 27\right.$ to $\left.105 \pm 15 \mathrm{~mL} / \mathrm{m}^{2}, p<0.001\right)$. Conclusions: Transcatheter, bilateral branch PA valve implantation was technically feasible with satisfactory efficacy and safety in patients with repaired Tetralogy of Fallot, severe pulmonary insufficiency, and oversized RV outflow tracts. Elimination of pulmonary insufficiency with this method resulted in reduced RV end-diastolic volume. 
This approach can be offered as an alternative to surgery, particularly in patients considered high risk for standard surgical placement and who are not candidates for the newer self-expanding valve prosthesis for placement in RV outflow tracts larger than 30 mm diameter.
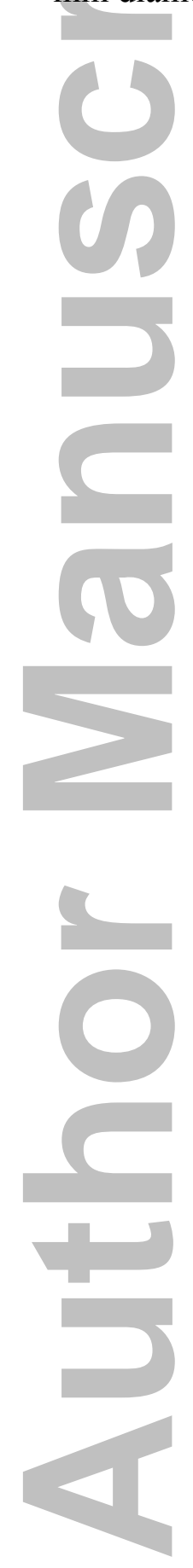


\section{INTRODUCTION}

Tetralogy of Fallot (TOF) is the most common cyanotic congenital heart defect, occurring in approximately 1 in 2,518 births in the United States (1). Surgical repair of

TOF most commonly includes performing a trans-annular patch, resulting in free pulmonary insufficiency, which is well tolerated in the pediatric population but often results in long-term complications including right ventricular (RV) dilation and dysfunction $(2,3)$, ventricular arrhythmias $(4)$, exercise limitations $(5,6)$ and sudden cardiac death (7). Severe pulmonary insufficiency, together with arrhythmias, symptoms, and/or moderate to severe RV enlargement, are indicators for pulmonary valve replacement (PVR) (8). Transcathter pulmomary valve implantation has revolutionized the treatment of pulmonary insufficiency, primarily for surgically placed RV to pulmonary artery (PA) conduits $(9,10)$. There is growing experience with valve implantation in non-conduit or native right ventricle outflow tracts (RVOT), usually preceded by bare metal pre-stenting (11). However, RVOTs greater than $30 \mathrm{~mm}$ diameter are not suitable for valve implantation due to the limitations of currently available transcatheter pulmonary valve sizes (largest diameter Sapien XT valve 29 mm, Edwards Lifesciences, Irvine, CA) (12). Therefore, there is a need for alternative trans-catheter treatment options in these patients.

Trans-catheter, bilateral branch PA valve implantation has been tested in an ovine model (13) and reported in two patients $(14,15)$. The efficacy and safety of this innovative approach in long-term follow-up has not been well described. At our institution, bare metal pre-stenting followed by bilateral branch PA valve implantation has been offered as 
an alternative to surgical valve placement in selected patients with repaired TOF and dysfunctional, large RVOT since 2011. This is the first report of this technique with short- and mid-term results using cardiac magnetic resonance imaging (CMR) RV

volume data.

\section{METHODS}

This was a retrospective analysis of 8 patients who underwent trans-catheter, bilateral branch PA valve implantation at the Children's Hospital of Michigan. In 4 patients, the procedure was performed due to other comorbid conditions, which were felt to increase the risk of surgical pulmonary valve replacement, though in 4 patients it was offered as a primary treatment alternative to surgical pulmonary valve placement (Supplemental

\section{Table 1).}

Data collected on the patients were demographic details of the patients, including patient age, sex, race, clinical characteristics, underlying anatomy, medications, details of the surgical repair, the results of the CMR as well as the echocardiograms performed at our center. The patients were NYHA classified according to their clinical status at time of procedure and follow-up. The echocardiograms were acquired at our center using a standard institutional protocol. CMR was performed using 1.5 Tesla scanners (GE Medical Systems). 1.5 Cine images were obtained using breath-hold SSPE method and were analyzed offline to assess the RV and LV end-diastolic volumes and end-systolic volumes by manually tracing the cavities at multiple levels by cardiologists and radiologists with expertise training. The entire RV was included in the measurement, 
including the RVOT and the area under the patch. Medis Mass software (version 6) was used for the tracings. The cine phase velocity pulse sequence was used to measure the PR fraction. The indication for re-establishment of pulmonary valve competence was significant RV enlargement (RV end-diastolic volume index $\geq 150 \mathrm{~mL} / \mathrm{m}^{2}$ and/or end systolic volume $\geq 80 \mathrm{~mL} / \mathrm{m}^{2}$ ) and/or symptoms of exercise intolerance due to pulmonary insufficiency. Appropriate candidates for bilateral branch PA valve implantation had RVOT diameter $>27 \mathrm{~mm}$ and branch PA diameter $<27 \mathrm{~mm}$. Procedural catheterization data was also analyzed. Post-valve implantation, patients were followed clinically and with repeat echocardiographic, and axial imaging evaluation. All angiographic images were reviewed and measured by 2 authors (NB and DK) who were blinded to the clinical outcomes, including narrowest PA branch diameter, sizing balloon waist and bare metal stent diameters, and valve stent final diameter. All the pre and post MRIs were reviewed and re-measured by two individual readers (MJZ and $\mathrm{AJ})$, blinded to the results, with expertise in reading cardiac MRIs. All measurements were made at best visualization (either antero-posterior or lateral view). The RVOT was measured at its narrowest diameter level and the PA was measured in systole at its narrowest diameter. The Wayne State University Institutional Research Board approved this study.

\section{Bilateral Branch PA Valve Implantation}

Cardiac catheterization was performed under general anesthesia. The baseline hemodynamic study was followed by angiography in the RVOT, PA, and coronary arteries. Patients were not thought to be candidates for primary native RVOT pre-stenting with valve implantation, due to significantly dilated RVOT $>30 \mathrm{~mm}$ in 6 patients and 
instability of a $30 \mathrm{~mm}$ diameter balloon inflated in the RVOT in 2 patients (RVOT diameter $28.6 \mathrm{~mm}$ ). Balloon sizing of the branch PAs were performed using either ZMed II or Tyshak II balloon catheters (NuMed, Inc., Hopkinton, NY). Balloon catheters that measured 3-4 $\mathrm{mm}$ in diameter greater than the largest diameter of the PA during systole were used. Balloon stability was achieved and balloon waist was measured.

Branch PA bare metal stent placement was performed prior to valve implantation in 14/15 PA. Palmaz-XL stents (Cordis Endovascular, Warren, NJ) were delivered with NuCLEUS balloon catheters (NuMed Corp, Hopkington, NY), with the intention to achieve a "dog-bone" shape in the bare metal stent (Fig. 1). Branch PA valve implantation was then performed. In circumstances where there was no discernable waist in the bare metal stent, a staged approach was taken to allow for bare metal endothelialization to avoid inadvertent stent embolization/malposition during stent valve implantation. Patients who underwent a staged approach had branch PA valve implantation at a separate catheterization 3-5 months later. Melody valves (Medtronic, Minneapolis, MN) were used when narrowest stented diameter was $\leq 24 \mathrm{~mm}$, whereas Sapien (XT or 3) valves were used for stented PA's $>24 \mathrm{~mm}$. Post-valve implantation, distal PA angiography was performed to show valve function (Fig. 2). If angiography raised a concern for valve dysfunction, intracardiac echocardiography was performed. All patients were observed overnight and started on aspirin prior to discharge.

\section{Statistical Analysis}

Catheterization and Cardiovascular Interventions 
The data were expressed as median (range), mean \pm standard deviation, or frequency $(\%)$ based on the type and distribution of data. The data before and after valve implantation were compared using a paired sample t-test. A $p<0.05$ was considered as statistically significant. The intra-class correlation coefficient (ICC) for inter-rater reliability for our two independent MRI readers was calculated. Statistical analysis was performed using SPSS version 24 (IBM, Armonk, NY). Cost analysis was performed with the matched controls of surgical PVR cases and the direct costs (including equipment, personnel, admission charges, medication charges etc) as well as indirect costs were reported. The average cost reported per case includes only the successful cases. The costs incurred due to the unsuccessful cases were not included in the cost assessment.

\section{RESULTS}

\section{Baseline Data}

A total of 8 patients underwent attempted bilateral branch PA valve implantation and 7 had successful implantation of the valves. (Table 1). 16 PAs were intended for treatment in 8 patients with 14 valves successfully implanted in 7 patients. All patients had the diagnosis of TOF, 6 patients with trans-annular patch augmentation of the RVOT and 2 with a limited trans-annular patch with homograft placement. All patients were adult size with median weight of $76 \mathrm{~kg}$ (range $43-99 \mathrm{~kg}$ ). Baseline transthoracic echocardiography showed free pulmonary insufficiency and a dilated right ventricle without RVOT obstruction. Pre-procedural axial imaging was cardiac MRI in 7 patients and cardiac computed tomography angiography due to the presence of a pacemaker in 1 patient. In all patients, the RVOT measured at least $27 \mathrm{~mm}$ at it's narrowest on cardiac imaging. 


\section{Cardiac Catheterization (Table 2)}

Angiography showed a significantly dilated RVOT with a median diameter of $30.6 \mathrm{~mm}$ (range $28.6-34.9 \mathrm{~mm}$ ), not suitable for trans-catheter pulmonary valve implantation in the RVOT. The branch PA had a wide variety of sizes and pulsatility, during balloon compliance testing. A smaller / stenotic branch PA (diameter $<16 \mathrm{~mm}$ by angiography) was noted in 6 branch PAs (40\%), each with a systolic pressure gradient $\geq 15 \mathrm{mmHg}$. Larger, dynamic branch PA (diameter $>20 \mathrm{~mm}$ ) was noted in $9(60 \%)$. The waist present in the sizing balloon was larger than the narrowest angiographic measurement by $2.9 \pm 1.6$

$\mathrm{mm}$.

Pre-stenting was performed in all branch PAs except in one patient (one PA), where the left pulmonary artery (LPA) was heavily calcified and non-pulsatile and was thought to provide a satisfactory landing zone for the Melody valve. For pre-stenting, primarily

Palmaz-XL stents were delivered on NuCLEUS balloons. A Genesis-XD stent was used in one patient. To ensure that the stents were adequately latched onto contractile branch PA, the stent-delivery balloon diameter was chosen significantly larger than the waist of sizing balloon by $4.0 \pm 1.7 \mathrm{~mm}$. For the branch PA valve implantation, Melody valve was used in 9 branch PAs and Sapien valve was used in 5 (Sapien XT n=2, Sapein 3 n=3)

branch PAs. A Sapien valve was chosen when the narrowest stent diameter was greater than $25 \mathrm{~mm}$. 
Hemodynamic data (Table 3A) showed the immediate positive effect of bilateral branch PA valve implantation. RV and distal PA systolic pressures were unchanged. Distal PA diastolic and mean pressures significantly increased, due to elimination of pulmonary insufficiency. When branch PA stenosis was present, the systolic pressure gradient from RV to distal PA was significantly decreased due to relief of PA stenosis by stent placement. The final stent diameter was larger than the baseline angiographic branch PA diameter by $5.3 \pm 2.9 \mathrm{~mm}$. Post-valve placement, distal PA angiography showed effective valve function in all except 1 valve, where there was moderate valve insufficiency of a Sapien XT valve placed in the LPA.

Bilateral branch PA stenting and valve implantation was technically successful in 7 out of 8 patients. There was a serious adverse event of stent embolization in one patient while retrieving the wire and catheter into the MPA. The embolized stent was successfully repositioned in the contralateral branch PA. A second stent was placed in the ipsilateral PA by oversizing it further. In another patient, the initial bare metal stent was placed in the LPA, though proximal migration was noted, requiring a second stent to be placed overlapping the distal $1 / 2$ of the initial stent, latching it on to the LPA. Due to jailing off of the RPA from the proximal bare metal stent, attempts to access the RPA were unsuccessful in this patient. This patient did not have bilateral PA valves placed and went for surgical placement of the pulmonary valve. There were no other complications. All patients were successfully discharged the following day.

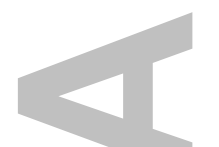

\section{Follow-up (Table 3B)}


Of the seven patients who underwent successful bilateral PA valve stent placement, the median clinical follow up was 10 months (range 3 months to 6 years). Symptomatically, four patients improved from NYHA class III to II and 3 remained with class II symptoms.

There have been no instances of endocarditis and no surgical or trans-catheter reinterventions required. Follow up transthoracic echocardiography showed none or trivial valve insufficiency in all but 1 patient having moderate insufficiency of a Sapien XT valve in the LPA. Follow-up CMR was performed in 5 patients at median follow up of 2 years (range 3 months to 6 years). Two patients refused follow-up CMR imaging. RV systolic and diastolic volumes were significantly decreased in all 5 patients and RV ejection fraction improved in 3 patients (Fig. 3). One patient with severe RV dilation (RV end diastolic volume index $195 \mathrm{~mL} / \mathrm{m} 2$ ) had a lower ejection fraction despite reduction in RV volume. No valve stent fractures were present on follow up chest radiography or fluoroscopy in all patients. The intra-class correlation coefficient (ICC) for inter-rater reliability for our two independent MRI readers was 0.9 for the RV volumes and 0.8 for the RVEF.

\section{Cost Analysis}

We performed cost analysis of this procedure, using 4 adult patients who underwent standard uncomplicated surgical valve placement in the RVOT position. Supplemental table 2 lists the demographic characteristics of the surgical cohort group, all of which were considered low risk. We combined the costs of both the BMS placement procedure and bilateral valve stent placement in our bilateral PA valve stent group. The average direct costs in the bilateral valve PA stent group (\$61,063/patient) were significantly 
higher than their surgical counterparts ( $\$ 34,729 /$ patient). As expected, the indirect costs were significantly higher in the surgical group $(\$ 16,342 /$ patient $)$ versus their trans catheter counterparts ( $\$ 8,799 /$ patient). The overall costs for surgical valve placement was $\$ 51,071 /$ patient and for the bilateral valved PA stent $\$ 69,862 /$ patient, with a differential cost just under $\$ 19,000$ favoring surgical pulmonary valve placement.

\section{DISCUSSION}

This report describes the technical feasibility, safety and efficacy of a staged, transcatheter bilateral branch PA valve implantation for treatment of pulmonary insufficiency in patients, whose RVOT measurements were too large to accommodate the current valve-stent maximal dimensions. This is the largest case series of this approach with intermediate follow up data. Implanted valves were fully functional in 13/14 (93\%) branch PAs. Furthermore, follow-up cardiac MRI showed reduction of the RV volume in five patients following valve placement.

Bilateral branch PA valve implantation was first described in an ovine model (13) and then in a human by Gillespie et al. in 2011 (14). Technical feasibility was shown, but no follow up data was described. The second case was published by Maschietto et al. in 2013; an 18-year-old male with dilated RVOT and right PA stenosis (15). Short-term (3 month) follow up data was available, with improved clinical symptoms (NYHA class III to II) and RV volume reduction on cardiac MRI. 
We report a series of 7 patients undergoing successful bilateral valve stent placement in the PAs, with a maximum follow up of 6 years, including 5 of the seven patients who underwent follow-up cardiac MRI. All implanted valves have remained functional without need for re-intervention, except one case of moderate valve insufficiency of the Sapien XT valve in the LPA, which is being followed conservatively. This valve was implanted on a smaller, pre-stented LPA (narrowest diameter $19 \mathrm{~mm}$ ) using $26 \mathrm{~mm}$ Sapien valve. The final diameter of valve measured $22.6 \mathrm{~mm}$, with moderate insufficiency noted by ICE imaging. We speculate that the valve insufficiency was secondary to not achieving full expansion of the Sapien valve, thereby not allowing full coaptation of the valve leaflets. Due to this experience, our practice has changed towards implanting a Melody valve when possible, which is more likely to be functional, even if not fully expanded.

This is a relatively new and experimental approach, which may be as effective in improving RV volume and hemodynamics as conventional RVOT valve implantation in patients with severe pulmonary insufficiency. Although our cohort had only 5 patients with follow up cardiac MRI, our data suggests that bilateral branch PA valve implantation had a favorable effect on RV volume and function. It is not uncommon in the repaired TOF population to have mild LV dysfunction, as a consequence of interventricular interactions from a dilated RV. However, the LV ejection fraction did not change in our cohort post valve implantation. In our cohort, one patient (patient \#5) had lower RV ejection fraction post-valve implantation. We speculate that this RV failed to 
remodel due to pre-procedural excessive RV volume overload (RV end diastolic volume index $\left.195 \mathrm{~mL} / \mathrm{m}^{2}\right)$.

In patients with larger PAs ( $>22 \mathrm{~mm})$, no PA stenosis, and absence of a balloon waist during sizing, we advocate a staged approach of bare metal PA stenting followed by valve implantation to create the solid landing zone for the valve stent. Our patients were brought back for valve implantation 3-5 months following initial bare metal PA stenting. Though there is no direct evidence when stents endothelialize, we believe this interval allows for endothelialization of the stent to the vascular wall, as suggested by animal studies on coronary stents which endothelialize in 2-3 weeks (16), preventing inadvertent stent embolization during subsequent valve stent implantation. Pre-stenting was performed in all branch PAs except in our first patient (one PA). In contrast to a homograft, the PA's have significantly less mobility, torque, and compressive forces resulting in fewer fractures. This is supported by the fact that RV to PA conduit stent fractures are significantly more common than PA stent fractures $(17,18)$.

In our opinion, balloon sizing is essential, as angiography underestimates the size and compliance of the pulsatile branch PAs. Our choice of stent delivery balloon for large branch PAs is the NuCLEUS balloon catheter (Numed Corp, Hopkington, NY), with a unique design incorporating a waist in the mid portion of the balloon. At a specified pressure, the central waist is designed to expand to $90 \%$ of the rated balloon diameter. When positioning the stent for delivery, the middle of NuCLEUS balloon catheter is positioned at the narrowest portion of branch PA (Fig. 1). Using this technique, the stent 
can be shaped as a dog-bone, flaring both the proximal and distal ends. This can minimize the risk of stent embolization and provide a better landing zone for the subsequently placed valve stent. A recently available alternative is the larger Balloon in Balloon (BIB) catheters, which also allow for precise positioning of larger stents.

There was one unsuccessful patient in whom the decision to implant bilateral stented valves was aborted. This was a 37-year-old female with TOF status post trans annular patch repair who has NYHA class III heart failure symptoms. Her cardiac MRI showed dilated RV with iRVEDV of $130 \mathrm{ml} / \mathrm{m} 2$. She was brought to the lab with the possibility of stents to be placed in her branch PA as her RVOT measured $34 \mathrm{~mm}$ at its narrowest segment. Since the Tyshak II 25X4 latched well in the proximal LPA segment a stent was mounted on the Nucleus $25 \times 5$ balloon catheter and advanced to the proximal LPA. Even though the initial appearance of the stent was satisfactory and there was no contrast observed around the stent on post-stent angiography, proximal displacement of the stent occurred during balloon withdrawal. Another Palmaz XL4010 stent was mounted on a Zmed II $26 \times 4 \mathrm{~cm}$ Balloon catheter and advanced to the proximal LPA to overlap the distal part of the previously placed stent. Unfortunately, due to jailing off of the proximal RPA, further attempts to access the RPA were unsuccessful and the procedure aborted. She was referred to surgical PVR.

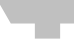

$\sqrt{1}$

In a cost analysis study from the U.S. markets, between trans-catheter pulmonary valve implantation and surgical PVR, although the cost for the Melody device and Ensemble (Medtronic, Minneapolis, Minnesota) delivery catheters were higher than the cost of the 
homograft/surgical valve, the hospital costs and physician fees were lower, which resulted in almost equivalent total costs (19). Vergales et al. noted a 5-year societal cost attributed to percutaneous PVR of $\$ 106,276$ and that for the traditional surgical conduit replacement at 5 years being higher at $\$ 141,273(20)$.

In our experience, this advantage favoring standard Melody valve placement in the RVOT position is eliminated in patients undergoing bilateral pulmonary valve stent placement. Surgical placement of pulmonary valves had lower overall costs than bilateral pulmonary valve stent placement. Though the surgical cohort were considered all low risk patients, with the bilateral pulmonary valve cohort having 4 moderate to high surgical risk, certainly the costs favor surgical valve placement in the low risk group. We also recognize that the endocarditis risk may be doubled, given the presence of two valve substrates. At this time, the physiologic implications of the RVOT dead space following bilateral branch PA valve implantation are unclear. It also remains unknown how the RV volume and function would be affected long-term with this procedure, though the early results are encouraging.

Soon, larger stents will be available for use in patients with transannular patch augmentation of the RVOT with dimensions $>30 \mathrm{~mm}$ in diameter. The Medtronic Harmony transcatheter pulmonary valve (Medtronic, Minneapolis, MN) is designed to treat larger native RVOT, with encouraging results shown in an early feasibility study (21), with a pivotal investigational device exemption study currently underway (22). 
Even with the development of oversized self-expanding stents, bilateral valve stent placement in the PA's may still play a role in a select group of patients. A recent paper by Lindsay et al, noted $9 \%$ of their patients showing aortic root compression in patients with stents being placed in the RVOT, especially oversized stents, such as the Sapien valve stent (23). Thus, we feel this technique described in our paper may still have relevance even after introduction of the larger stent size valve series.

\section{Limitations}

This was a retrospective study with an inherent limitation. Our cohort was small, although this is the largest series describing this technique. Follow-up CMR was not obtained in 2 patients, due to loss to follow-up. We do not believe this affects the reporting of our post-valve CMR data. However, the possibility of a selection bias cannot be excluded.

\section{CONCLUSION}

Trans-catheter, bilateral branch PA valve implantation was technically feasible with satisfactory hemodynamic benefit and safety for the treatment of severe pulmonary insufficiency in patients with repaired TOF and oversized RVOT. Competency of the valves placed in the branch PAs resulted in RV volume reduction by CMR. However, the in-hospital costs were significantly higher in the bilateral pulmonary valve group. This technique could be offered to patients as an alternative to surgery, though we would recommend this procedure, after consultation with the surgeons, only to patients 
considered moderate to high risk for standard surgical placement of a pulmonary valve in the RVOT position.
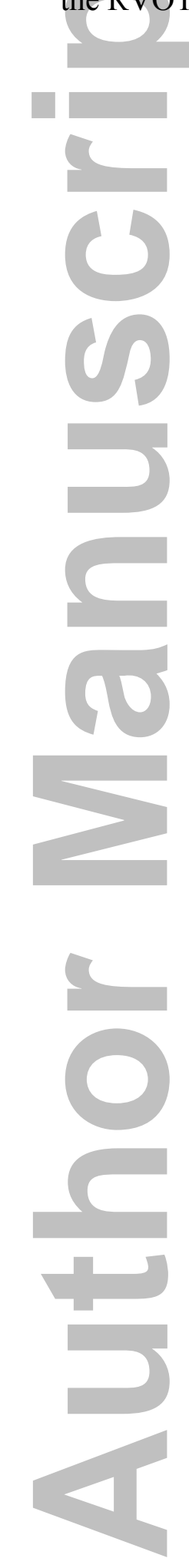


\section{REFERENCES:}

1. Parker SE, Mai CT, Canfield MA, et al. Updated National Birth Prevalence estimates for selected birth defects in the United States, 2004-2006. Birth Defects Res A Clin Mol Teratol. 2010;88(12):1008-1016.

2. Bove EL, Byrum CJ, Thomas FD, et al. The influence of pulmonary insufficiency on ventricular function following repair of tetralogy of Fallot. Evaluation using radionuclide ventriculography. J Thorac Cardiovasc Surg. 1983;85(5):691-696.

3. Niezen RA, Helbing WA, van der Wall EE, et al. Biventricular systolic function and mass studied with MR imaging in children with pulmonary regurgitation after repair for tetralogy of Fallot. Radiology. 1996;201(1):135-140.

4. Gatzoulis MA, Till JA, Somerville J, et al. Mechanoelectrical interaction in tetralogy of Fallot. QRS prolongation relates to right ventricular size and predicts malignant ventricular arrhythmias and sudden death. Circulation. 1995;92(2):231237.

5. Rowe SA, Zahka KG, Manolio TA, et al. Lung function and pulmonary regurgitation limit exercise capacity in postoperative tetralogy of Fallot. J Am Coll Cardiol. 1991;17(2):461-466.

6. Kondo C, Nakazawa M, Kusakabe K, et al. Left ventricular dysfunction on exercise long-term after total repair of tetralogy of Fallot. Circulation. 1995;92(9 Suppl):II250-255.

7. Gatzoulis MA, Balaji S, Webber SA, et al. Risk factors for arrhythmia and sudden cardiac death late after repair of tetralogy of Fallot: a multicentre study. Lancet. 2000;356(9234):975-981. 
8. Geva T. Repaired tetralogy of Fallot: the roles of cardiovascular magnetic resonance in evaluating pathophysiology and for pulmonary valve replacement decision support. J Cardiovasc Magn Reson. 2011;13:9.

9. Cheatham JP, Hellenbrand WE, Zahn EM, et al. Clinical and hemodynamic outcomes up to 7 years after transcatheter pulmonary valve replacement in the US melody valve investigational device exemption trial. Circulation.

2015;131(22):1960-1970.

10. Ansari MM, Cardoso R, Garcia D, et al. Percutaneous Pulmonary Valve Implantation: Present Status and Evolving Future. J Am Coll Cardiol. 2015;66(20):2246-2255.

11. Meadows JJ, Moore PM, Berman DP, et al. Use and performance of the Melody Transcatheter Pulmonary Valve in native and postsurgical, nonconduit right

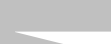
ventricular outflow tracts. Circ Cardiovasc Interv. 2014;7(3):374-380.

12. Holzer RJ, Hijazi ZM. Transcatheter pulmonary valve replacement: State of the art. Catheter Cardiovasc Interv. 2016;87(1):117-128.

13. Robb JD, Harris MA, Minakawa M, et al. Melody valve implantation into the branch pulmonary arteries for treatment of pulmonary insufficiency in an ovine model of right ventricular outflow tract dysfunction following tetralogy of Fallot repair. Circ Cardiovasc Interv. 2011;4(1):80-87.

14. Gillespie MJ, Dori Y, Harris MA, et al. Bilateral branch pulmonary artery melody valve implantation for treatment of complex right ventricular outflow tract dysfunction in a high-risk patient. Circ Cardiovasc Interv. 2011;4(4):e21-23. 
15. Maschietto N, Milanesi O. A concert in the heart: bilateral Melody valve implantation in the branch pulmonary arteries. J Invasive Cardiol. 2013;25(4):E69-71.

16. Van Belle E, Tio FO, Couffinhal T, et al. Stent endothelialization. Time course, impact of local catheter delivery, feasibility of recombinant protein administration, and response to cytokine expedition. Circulation. 1997;95(2):438448.

17. Breinholt JP, Nugent AW, Law MA, et al. Stent fractures in congenital heart disease. Catheter Cardiovasc Interv. 2008;72(7):977-982.

18. McElhinney DB, Bergersen L, Marshall AC. In situ fracture of stents implanted for relief of pulmonary arterial stenosis in patients with congenitally malformed hearts. Cardiol Young. 2008;18(4):405-414.

19. Gatlin SW, Kim DW, Mahle WT. Cost analysis of percutaneous pulmonary valve replacement. Am J Cardiol. 2011;108(4):572-574.

20. Vergales JE, Wanchek T, Novicoff W, et al. Cost-analysis of percutaneous pulmonary valve implantation compared to surgical pulmonary valve replacement. Catheter Cardiovasc Interv. 2013;82(7):1147-1153.

21. Benson LB, Lisa; McHenry, Brian T; Gillespie, Matthew; Cheatham, John P. JCT-613 One Year Outcomes from the Early Feasibility Study of the Harmony Transcatheter Pulmonary Valve. Journal of the American College of Cardiology. 2016;Suppl S(68.18):B250.

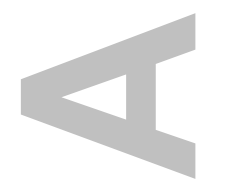


22. Cheatham JP. The Medtronic Harmony ${ }^{\mathrm{TM}}$ Transcatheter Pulmonary Valve Clinical Study. ClinicalTrials.gov [Internet]. updated 2017 Jan 13, 2017; cited 2017 Mar 4:Available from: https://clinicaltrials.gov/show/NCT02979587.

23. Lindsay I, Aboulhosn J, Salem M, et al. Aortic root compression during transcatheter pulmonary valve replacement. Catheter Cardiovasc Interv. 2016;88(5):814-821.
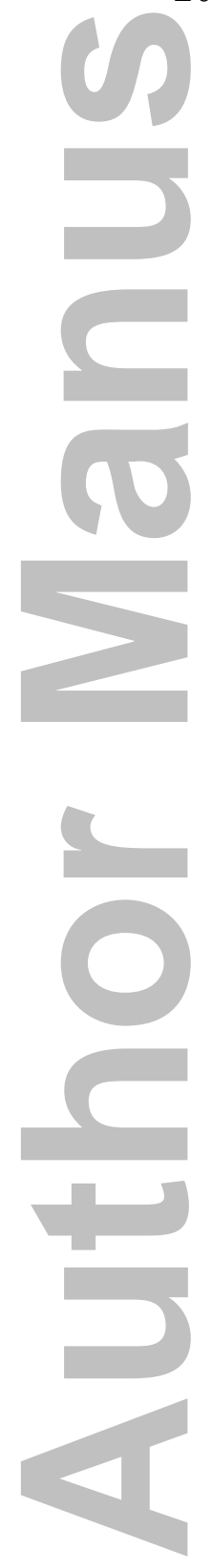


\section{FIGURE LEGEND}

Figure 1. Pre-stenting and Melody valve placement, proximal right pulmonary artery (RPA). (A) Baseline angiography shows a pulsatile proximal RPA. In systole, there is mild narrowing (b: $20.2 \mathrm{~mm})$ compared to distal (a: $27.2 \mathrm{~mm})$ and proximal (c: $27.3 \mathrm{~mm})$ segment of RPA. (B) Balloon sizing of RPA shows a minimal balloon waist of $23.2 \mathrm{~mm}$. (C) Pre-stenting using a Palmaz-XL 4010 stent mounted on a $25 \mathrm{~mm}$ x $4 \mathrm{~cm}$ NuCLEUS balloon catheter through a 12-Fr Flexor sheath. The stent is implanted so that a dog-bone shape is achieved to avoid embolization. (D) Post-stent angiography shows mild stent waist (b: $21.7 \mathrm{~mm}$ ), compared to the distal (a: $24.9 \mathrm{~mm}$ ) and proximal $(24.9 \mathrm{~mm})$ ends of stent. (E) Melody valve placement in RPA. Melody TPV 22 (PB1018) is implanted on 24 mm x $4 \mathrm{~cm}$ NuMed BIB catheter. (F) Post-Melody in RPA. There is no insufficiency of Melody valve.

Figure 2. Pre- and post-bilateral branch pulmonary artery (PA) valve implantation. (A) Baseline PA angiography. Right ventricular outflow tract is dilated. Proximal LPA is heavily calcified with no stenosis or pulsatility. There is a stent in proximal RPA. (B) Post-valve implantation. Simultaneous bilateral distal PA angiography shows no valve insufficiency. In this case, pre-stenting was not performed in the LPA due to a satisfactory landing zone.

Figure 3. Comparison of cardiac magnetic resonance imaging before and after bilateral branch pulmonary artery valve implantation in five patients.

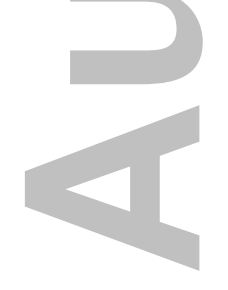




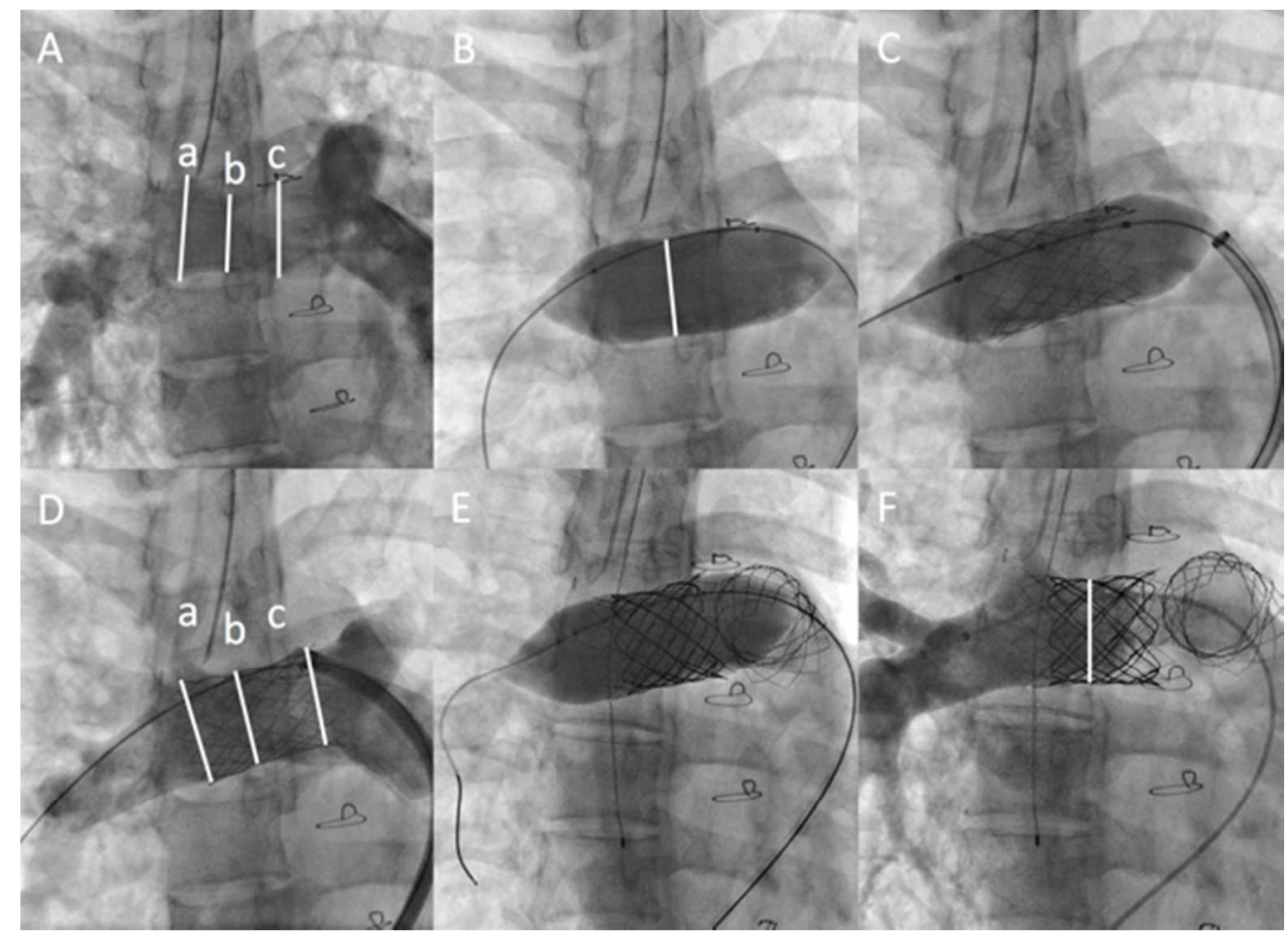

Figure 1. Pre-stenting and Melody valve placement, proximal right pulmonary artery (RPA). (A) Baseline angiography shows a pulsatile proximal RPA. In systole, there is mild narrowing (b: $20.2 \mathrm{~mm}$ ) compared to distal (a: $27.2 \mathrm{~mm}$ ) and proximal (c: $27.3 \mathrm{~mm}$ ) segment of RPA. (B) Balloon sizing of RPA shows a minimal balloon waist of $23.2 \mathrm{~mm}$. (C) Pre-stenting using a Palmaz-XL 4010 stent mounted on a $25 \mathrm{~mm} \times 4 \mathrm{~cm}$ NuCLEUS balloon catheter through a 12-Fr Flexor sheath. The stent is implanted so that a dog-bone shape is achieved to avoid embolization. (D) Post-stent angiography shows mild stent waist (b: $21.7 \mathrm{~mm}$ ), compared to the distal (a: $24.9 \mathrm{~mm}$ ) and proximal $(24.9 \mathrm{~mm}$ ) ends of stent. (E) Melody valve placement in RPA. Melody TPV 22 (PB1018) is implanted on $24 \mathrm{~mm} \times 4 \mathrm{~cm}$ NuMed BIB catheter. (F) Post-Melody in RPA. There is no insufficiency of Melody valve.

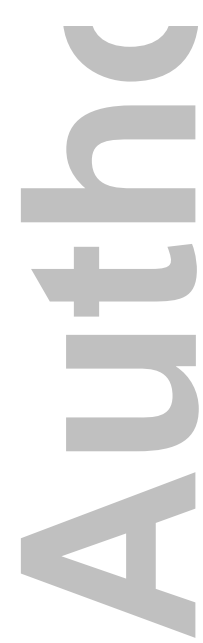

$54 \times 39 \mathrm{~mm}(300 \times 300$ DPI $)$ 


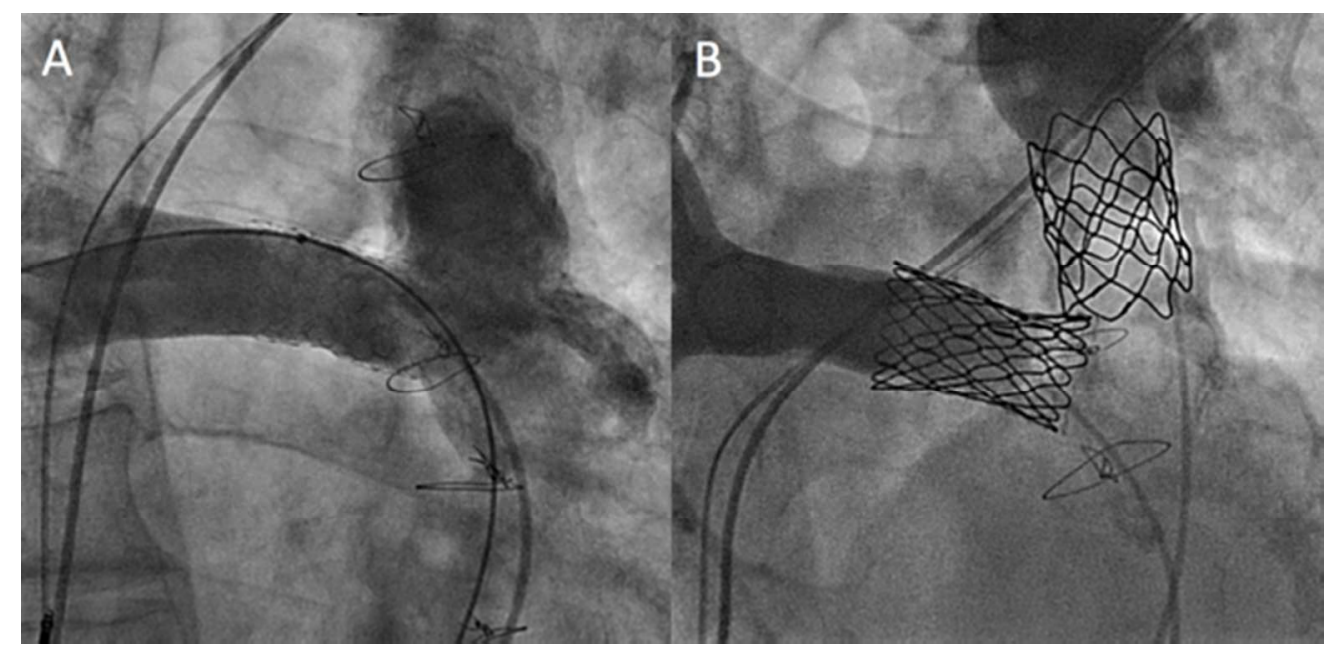

Figure 2. Pre- and post-bilateral branch pulmonary artery (PA) valve implantation. (A) Baseline PA angiography. Right ventricular outflow tract is dilated. Proximal LPA is heavily calcified with no stenosis or pulsatility. There is a stent in proximal RPA. (B) Post-valve implantation. Simultaneous bilateral distal PA angiography shows no valve insufficiency. In this case, pre-stenting was not performed in the LPA due to a satisfactory landing zone.

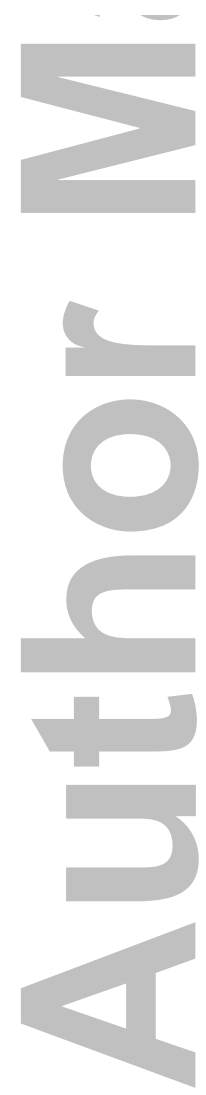

$54 \times 26 \mathrm{~mm}(300 \times 300 \mathrm{DPI})$ 


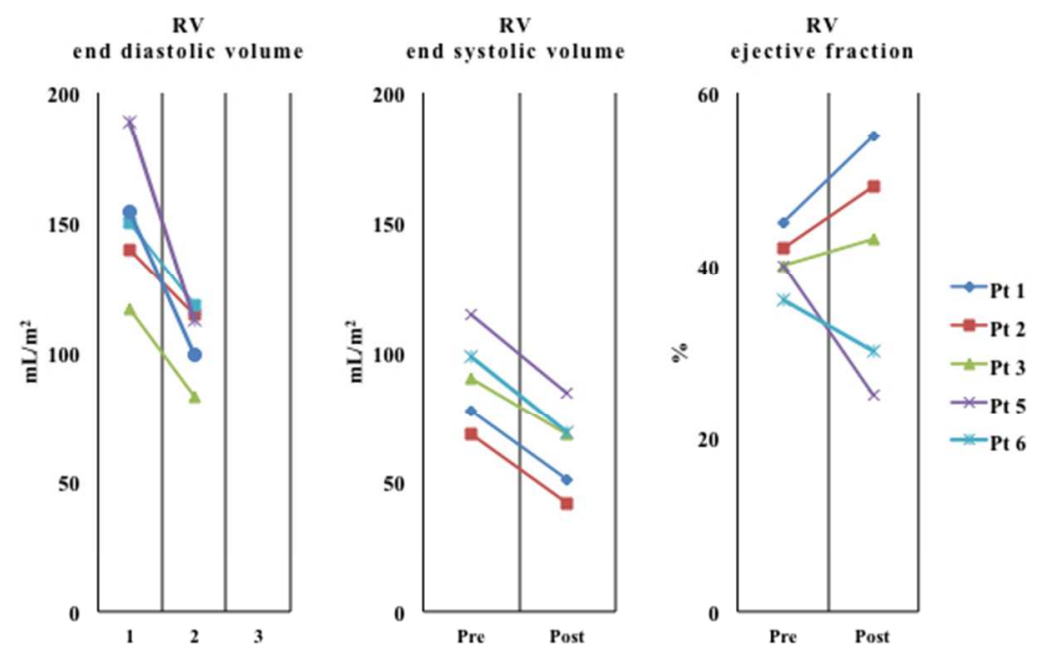

Figure 3. Comparison of cardiac magnetic resonance imaging before and after bilateral branch pulmonary artery valve implantation in five patients.

$254 \times 190 \mathrm{~mm}(72 \times 72 \mathrm{DPI})$

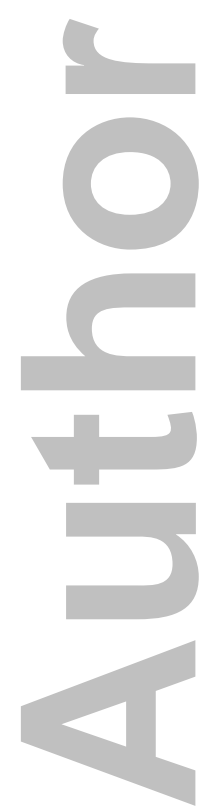


Table 1. Baseline demographic and cardiac magnetic resonance (CMR) data.

\begin{tabular}{|c|c|c|c|c|c|c|c|c|c|c|c|}
\hline \multirow[b]{2}{*}{$\mathrm{Pt}$} & \multirow[b]{2}{*}{$\begin{array}{c}\text { Age } \\
\text { (year) }\end{array}$} & \multirow[b]{2}{*}{ Gender } & \multirow[b]{2}{*}{$\begin{array}{c}\text { Weight } \\
(\mathrm{kg})\end{array}$} & \multirow[b]{2}{*}{$\begin{array}{c}\text { NYHA } \\
\text { class }\end{array}$} & \multicolumn{7}{|c|}{ Cardiac MR } \\
\hline & & & & & $\begin{array}{l}\text { RVEDV } \\
\text { index } \\
(\mathrm{mL} / \mathrm{m} 2)\end{array}$ & $\begin{array}{l}\text { RVESV } \\
\text { index } \\
(\mathrm{mL} / \mathrm{m} 2)\end{array}$ & $\begin{array}{c}\text { RV } \\
\text { ejection } \\
\text { fraction }\end{array}$ & $\begin{array}{l}\text { Pulmonary } \\
\text { regurgitation } \\
\text { fraction }\end{array}$ & $\begin{array}{l}\text { RVOT } \\
(\mathrm{mm})\end{array}$ & $\begin{array}{l}\text { RPA } \\
(\mathrm{mm})\end{array}$ & $\begin{array}{l}\text { LPA } \\
(\mathrm{mm})\end{array}$ \\
\hline 1 & 57 & $\mathrm{M}$ & 76.6 & III & 139 & 77 & $45 \%$ & $35 \%$ & 27.3 & 10 & 15.6 \\
\hline 2 & 36 & $\mathrm{M}$ & 82 & III & 122 & 74 & $40 \%$ & $35 \%$ & 27.9 & 18.9 & 8.6 \\
\hline 3 & 26 & $\mathrm{~F}$ & 43.7 & II & 146 & 87 & $40 \%$ & $69 \%$ & 31.2 & 22.2 & 14.2 \\
\hline 4 & 20 & $\mathrm{~F}$ & 61.1 & II & 162 & 85 & $47 \%$ & $46 \%$ & 31.8 & 21.3 & 19.8 \\
\hline 5 & 49 & F & 89.3 & III & 195 & 115 & $41 \%$ & $61 \%$ & 29.5 & 19.8 & 16.4 \\
\hline 6 & 16 & $\mathrm{M}$ & 55.9 & II & 149 & 94 & $37 \%$ & $39 \%$ & 31.5 & 22.8 & 10.7 \\
\hline 7 & 67 & $M$ & 99.8 & III & \multicolumn{4}{|c|}{ NA* } & 30.9 & 20.8 & 25.4 \\
\hline
\end{tabular}

Abbreviations: RVEDV, right ventricle end diastolic volume; RVESV, right ventricle end systolic volume; RVOT, right ventricle outflow tract; RPA, right pulmonary artery; LPA, left pulmonary artery *Cardiac CT angiography was used as a pre-procedural assessment, because of presence of pacemaker. 
Table 2. Catheterization data on bilateral branch pulmonary artery stenting and valve implantation

\begin{tabular}{|c|c|c|c|c|c|c|c|c|c|c|c|c|}
\hline \multirow{2}{*}{\multicolumn{2}{|c|}{\begin{tabular}{l|l}
0 & $\mathrm{P}$ \\
1 & \\
2 & \\
3 & \\
4 &
\end{tabular}}} & \multirow[b]{2}{*}{$\begin{array}{c}\text { Branch } \\
\text { PA }\end{array}$} & \multicolumn{2}{|c|}{ Baseline } & \multicolumn{3}{|c|}{ Pulmonary artery stenting } & \multirow[t]{2}{*}{$\begin{array}{c}\text { Interval } \\
\text { Time } \\
\text { (months) } \\
\end{array}$} & \multicolumn{3}{|c|}{$\begin{array}{c}\text { Bilateral branch pulmonary valve } \\
\text { implantation }\end{array}$} & \multirow[b]{2}{*}{$\begin{array}{c}\text { Final } \\
\text { valve } \\
\text { stent } \\
\text { diameter } \\
(\mathrm{mm})\end{array}$} \\
\hline & & & $\begin{array}{l}\text { Angio } \\
(\mathrm{mm})\end{array}$ & $\begin{array}{l}\text { Balloon } \\
\text { Sizing } \\
\text { Waist } \\
(\mathrm{mm})\end{array}$ & Stent & Balloon & $\begin{array}{l}\text { Waist } \\
\text { of } \\
\text { stent } \\
(\mathrm{mm})\end{array}$ & & $\begin{array}{l}\text { Type of } \\
\text { valve }\end{array}$ & $\begin{array}{c}\text { Valve } \\
\text { deployme } \\
\text { nt } \\
\text { balloon } \\
\text { size } \\
(\mathrm{mm})\end{array}$ & $\begin{array}{l}\text { Angiographic } \\
\text { valve } \\
\text { insufficiency }\end{array}$ & \\
\hline \multirow{2}{*}{\multicolumn{2}{|c|}{1}} & RPA & 10.9 & NA & $\begin{array}{l}\text { Genesis PG } \\
3910\end{array}$ & $\begin{array}{l}\text { Z-Med II } 16 \mathrm{~mm} \\
\times 2 \mathrm{~cm}\end{array}$ & 15 & 5 & Melody & 18 & None & 14.3 \\
\hline & & LPA & 15.2 & 16.4 & \multicolumn{3}{|c|}{$\begin{array}{l}\text { No pre-stenting done due to heavily } \\
\text { calcified LPA }\end{array}$} & & Melody & 18 & None & 18.5 \\
\hline $\begin{array}{l}9 \\
0\end{array}$ & \multirow{2}{*}{2} & RPA & 18.3 & 21.0 & $\begin{array}{l}\text { Palmaz XL } \\
\text { P4010 }\end{array}$ & $\begin{array}{l}\text { NuCLEUS } 25 \\
\mathrm{~mm} \times 4 \mathrm{~cm}\end{array}$ & 21.3 & \multirow{2}{*}{4} & Melody & 22 & None & 22.9 \\
\hline $\begin{array}{l}1 \\
2\end{array}$ & & LPA & 12.3 & 13.5 & $\begin{array}{c}\text { Palmaz XL } \\
\text { P4010 }\end{array}$ & $\begin{array}{c}\text { Z-Med II } 20 \\
\mathrm{~mm} \times 2 \mathrm{~cm}\end{array}$ & 18.0 & & Melody & 20 & None & 20.2 \\
\hline $\begin{array}{l}3 \\
4\end{array}$ & \multirow{2}{*}{3} & RPA & 21.0 & 21.3 & $\begin{array}{l}\text { Palmaz XL } \\
\text { P4010 }\end{array}$ & $\begin{array}{c}\text { NuCLEUS } 25 \\
\mathrm{~mm} \times 4 \mathrm{~cm}\end{array}$ & 22.3 & \multirow{2}{*}{5} & Melody & 24 & None & 22.6 \\
\hline $\begin{array}{l}5 \\
6\end{array}$ & & LPA & 9.3 & 15.9 & $\begin{array}{c}\text { Palmaz XL } \\
\text { P3110 }\end{array}$ & $\begin{array}{c}\text { BIB } 22 \mathrm{~mm} \times 4 \\
\mathrm{~cm}\end{array}$ & 22.3 & & Melody & 24 & None & 21.7 \\
\hline $\begin{array}{l}7 \\
8\end{array}$ & \multirow{2}{*}{4} & RPA & 20.2 & 23.2 & $\begin{array}{l}\text { Palmaz XL } \\
\text { P4010 }\end{array}$ & $\begin{array}{c}\text { NuCLEUS } 25 \\
\mathrm{~mm} \times 4 \mathrm{~cm}\end{array}$ & 21.7 & \multirow{2}{*}{4} & Melody & 24 & None & 23.4 \\
\hline $\begin{array}{l}9 \\
0\end{array}$ & & LPA & 18.0 & 22.0 & $\begin{array}{c}\text { Palmaz XL } \\
\text { P4010 }\end{array}$ & $\begin{array}{l}\text { NuCLEUS } 25 \\
\mathrm{~mm} \times 4 \mathrm{~cm}\end{array}$ & 19.2 & & Melody & 24 & None & 23.6 \\
\hline $\begin{array}{l}1 \\
2\end{array}$ & \multirow{2}{*}{5} & RPA & 22.0 & 24.9 & $\begin{array}{c}\text { Palmaz XL } \\
\text { P5010 }\end{array}$ & $\begin{array}{c}\text { NuCLEUS } 28 \\
\mathrm{~mm} \times 4 \mathrm{~cm}\end{array}$ & 24.8 & \multirow{2}{*}{3} & $\begin{array}{c}\text { Sapien } \\
\text { XT }\end{array}$ & 29 & None & 26.0 \\
\hline $\begin{array}{l}3 \\
4\end{array}$ & & LPA & 15.2 & 17.9 & $\begin{array}{l}\text { Palmaz XL } \\
\text { P4010 }\end{array}$ & $\begin{array}{c}\text { NuCLEUS } 25 \\
\mathrm{~mm} \times 4 \mathrm{~cm}\end{array}$ & 19.0 & & $\begin{array}{l}\text { Sapien } \\
\mathrm{XT}\end{array}$ & 26 & Moderate & 22.6 \\
\hline $\begin{array}{l}5 \\
6\end{array}$ & \multirow{2}{*}{6} & RPA & 22.3 & 25.8 & $\begin{array}{c}\text { Palmaz XL } \\
\text { P4010 }\end{array}$ & $\begin{array}{c}\text { NuCLEUS } 28 \\
\mathrm{~mm} \times 4 \mathrm{~cm}\end{array}$ & 25.1 & \multirow{2}{*}{3} & $\begin{array}{c}\text { Sapien } \\
3 \\
\end{array}$ & 29 & None & 26.5 \\
\hline $\begin{array}{l}7 \\
8\end{array}$ & & LPA* & 10.9 & 15.3 & $\begin{array}{l}\text { Palmaz XL } \\
\text { P3110 }\end{array}$ & $\begin{array}{c}\text { BIB } 18 \mathrm{~mm} \times 4 \\
\mathrm{~cm}\end{array}$ & 15.2 & & Melody & 20 & None & 17.4 \\
\hline $\begin{array}{l}9 \\
0\end{array}$ & \multirow{2}{*}{7} & RPA & 23.3 & 26.2 & $\begin{array}{c}\text { Palmaz XL } \\
\text { P4010 } \\
\end{array}$ & $\begin{array}{c}\text { NuCLEUS } 30 \\
\mathrm{~mm} \times 4 \mathrm{~cm}\end{array}$ & 25.7 & \multirow{2}{*}{4} & $\begin{array}{c}\text { Sapien } \\
3 \\
\end{array}$ & 29 & None & 28 \\
\hline $\begin{array}{l}1 \\
2\end{array}$ & & LPA & 21.5 & 23.6 & $\begin{array}{c}\text { Palmaz XL } \\
\text { P4010 }\end{array}$ & $\begin{array}{c}\text { NuCLEUS } 28 \\
\mathrm{~mm} \times 3 \mathrm{~cm}\end{array}$ & 25.0 & & $\begin{array}{c}\text { Sapien } \\
3 \\
\end{array}$ & 29 & None & 28 \\
\hline
\end{tabular}

3 *LPA stent embolization: Initially, LPA was stented by $29 \mathrm{~mm}$ length Genesis XD mounted on $16 \mathrm{~mm}$ $4 \times 3 \mathrm{~cm}$ Z-Med II balloon. This stent embolized into the main pulmonary artery and re-positioned in the 5 proximal stented RPA, followed by further dilation using a $24 \mathrm{~mm}$ x $4 \mathrm{~cm}$ ATLAS Gold balloon. 
Table 3. Improvement of clinical variables before and after bilateral branch pulmonary artery valve implantation

(A) Immediate hemodynamic effect in cardiac catheterization

\begin{tabular}{|c|c|c|c|c|}
\hline & \multicolumn{2}{|l|}{ Variables } & Baseline & $\begin{array}{l}\text { Post-valve } \\
\text { implantation }\end{array}$ \\
\hline DV prose & \multicolumn{2}{|c|}{ Systolic $(\mathrm{mmHg})$} & $40 \pm 14$ & $35 \pm 5$ \\
\hline RV pressure & \multicolumn{2}{|c|}{$\%$ systemic } & $42 \pm 12$ & $38 \pm 8$ \\
\hline \multirow{4}{*}{$\begin{array}{l}\text { Distal PA } \\
\text { pressure }\end{array}$} & \multicolumn{2}{|c|}{ Systolic (mmHg) } & $28 \pm 12$ & $29 \pm 4$ \\
\hline & \multicolumn{2}{|c|}{ Diastolic $(\mathrm{mmHg})$} & $7 \pm 4$ & $12 \pm 3$ \\
\hline & \multicolumn{2}{|c|}{ Mean $(\mathrm{mmHg})$} & $15 \pm 5$ & $19 \pm 3$ \\
\hline & \multicolumn{2}{|c|}{ Systolic pressure gradient $(\mathrm{mmHg})$} & $13 \pm 9$ & $6 \pm 7$ \\
\hline \multirow{5}{*}{ Angiography } & \multicolumn{2}{|c|}{ Narrowest diameter of branch PA (mm) } & $16.3 \pm 4.7$ & $21.7 \pm 3.5$ \\
\hline & \multirow{4}{*}{ Valve insufficiency } & None/trivial & 0 & $13 / 14(93 \%)$ \\
\hline & & Mild & 0 & 0 \\
\hline & & Moderate & 0 & $1 / 14(7 \%)$ \\
\hline & & Severe & $7 / 7(100 \%)$ & 0 \\
\hline
\end{tabular}

(B)

Follow up data

\begin{tabular}{|c|c|c|c|c|c|}
\hline & \multicolumn{2}{|c|}{ Variables } & Baseline & $\begin{array}{l}\text { Post-valve } \\
\text { implantation }\end{array}$ & $p$ value \\
\hline \multirow{2}{*}{ Symptoms } & \multirow{2}{*}{ NYHA } & Class II & $3 / 7(43 \%)$ & $7 / 7(100 \%)$ & \multirow{2}{*}{ NA } \\
\hline & & Class III & $4 / 7(57 \%)$ & 0 & \\
\hline \multirow{4}{*}{$\begin{array}{c}\text { Cardiac MRI } \\
\text { (4 patients) }\end{array}$} & \multicolumn{2}{|c|}{$\mathrm{RV}$ end diastolic volume index $(\mathrm{mL} / \mathrm{m} 2)$} & $150 \pm 27$ & $105 \pm 15$ & $<0.001$ \\
\hline & \multicolumn{2}{|c|}{$\mathrm{RV}$ end systolic volume index $(\mathrm{mL} / \mathrm{m} 2)$} & $90 \pm 18$ & $63 \pm 17$ & $<0.001$ \\
\hline & \multicolumn{2}{|c|}{ RV ejection fraction $(\%)$} & $40 \pm 3$ & $40 \pm 13$ & 0.43 \\
\hline & \multicolumn{2}{|c|}{ LV ejection fraction $(\%)$} & $60 \pm 3$ & $59 \pm 5$ & NA \\
\hline \multirow{4}{*}{ Echocardiography } & \multirow{4}{*}{ Valve insufficiency } & None/trivial & 0 & $13 / 14(93 \%)$ & \multirow{4}{*}{ NA } \\
\hline & & Mild & 0 & 0 & \\
\hline & & Moderate & 0 & $1 / 14(7 \%)$ & \\
\hline & & Severe & $7 / 7(100 \%)$ & 0 & \\
\hline
\end{tabular}




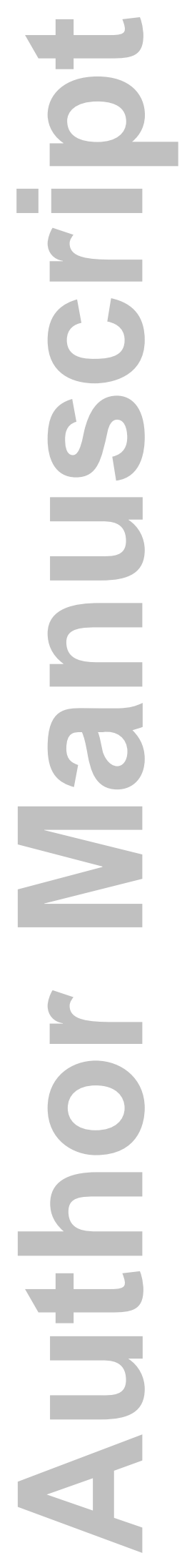

Catheterization and Cardiovascular Interventions

This article is protected by copyright. All rights reserved. 
Supplemental Table 1: Reasons for bilateral branch PA valve implantation

\begin{tabular}{|l|l|}
\hline Patient $\#$ & Reason for bilateral branch PA valve implantation \\
\hline 1 & $\begin{array}{l}\text { Ventricular tachycardia induced relatively poor cardiac function s/p ICD } \\
\text { implantation }\end{array}$ \\
\hline 2 & Tachyarrhythmia induced relatively poor cardiac function \\
\hline 3 & Patient preference \\
\hline 4 & Tachyarrhythmia induced relatively poor cardiac function \\
\hline 5 & Patient preference \\
\hline 6 & Patient preference \\
\hline 7 & Relatively Poor Cardiac function \\
\hline 8 & Patient preference \\
\hline
\end{tabular}

Supplemental Table 2: Surgical PVR comparative group

\begin{tabular}{|l|l|l|l|l|}
\hline Pt & Age (year) & Gender & Weight $(\mathrm{kg})$ & Length of Stay \\
\hline 1 & 16 & M & 115 & 4 \\
\hline 2 & 32 & M & 71 & 4 \\
\hline 3 & 16 & F & 76 & 4 \\
\hline 4 & 19 & M & 91 & 6 \\
\hline 5 & 20 & F & 67 & 3 \\
\hline
\end{tabular}

5

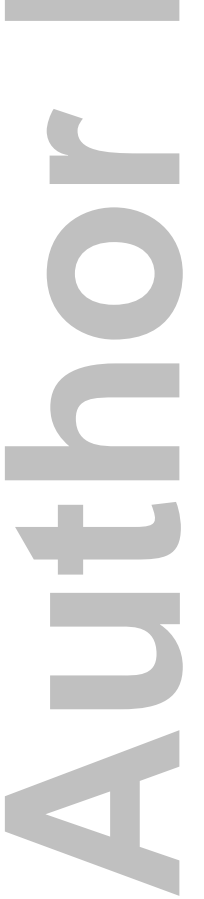

